\title{
PREDICTION OF STATIC CRACK PROPAGATION IN ADHESIVE JOINTS
}

\author{
Reza Hedayati, Meysam Jahanbakhshi \\ Young Researchers and Elite Club, Najaf Abad Branch, Islamic Azad University, Najaf Abad, Isfahan, Iran \\ e-mail: rezahedayati@gmail.com; jahanbakhshimeysam@gmail.com \\ Saeid Ghorbani Khouzani \\ Department of Mechanical Engineering, Khomeini Shahr Branch, Islamic Azad University, Isfahan, Iran \\ e-mail:saeid.ghorbani@iaukhsh.ac.ir
}

\begin{abstract}
In this work, fracture mechanics methodology is used to predict crack propagation in the adhesive joining of aluminum and composite plates. Three types of loadings and two types of glass-epoxy composite sequences: $[0 / 90]_{2 \mathrm{~s}}$ and $[0 / 45 /-45 / 90]_{\mathrm{s}}$ are considered for the composite plate. Therefore $2 \times 3=6$ cases are considered and their results are compared. The debonding initiation load, complete debonding load, crack face profile and load-displacement diagram have been compared for the six cases.
\end{abstract}

Keywords: fracture, adhesive joint, debonding, APDL, LEFM

\section{Introduction}

With the increase in the number of bonded composite aircraft components and in the number of bonded repairs made to cracked metallic structures, knowledge of adhesive bonding is becoming crucial to aircraft design and life extension. Design and analysis of adhesively bonded joints has traditionally been performed using a variety of stress-based approaches (Tomblin et al., 1998). The use of fracture mechanics has become increasingly popular for the analysis of metallic components but has been oflimited use in bonded structure joints. Durability and damage tolerance guidelines, already in existence for metallic aircraft structures, need to be developed for bonded structures, and fracture mechanics provides one method for doing so(Tomblin et al., 1998).

Previous research in the field of bonded joint analysis and design may be grouped into two major areas of emphasis (Tomblin et al., 1998). The first, a stress-based approach, was initiated by Goland and Reissner (1944) and has been used extensively by Hart-Smith (1983), Hart-Smith and Thrall (1985), and others. This approach has focused on determining the distribution of shear and normal (or peel) stresses within the adhesive bond line under static loading conditions. In their seminal work, Goland and Reissner (1944) investigated single lap shear joints with thin (inflexible) and thick (flexible) adhesive layers. Their results indicated that both shear and normal stresses approach maxima at or near the free edge of the joint (Tomblin et al., 1998).

Adams (1991) confirmed this observation and, using a finite element analysis, proposed that failure of the adhesive layer occurs in tension due to high peel stresses rather than in shear as suggested by the lap shear joint name. Because of the importance of the peel stresses, they have been incorporated into bonded joint design and current criteria call for their elimination or drastic reduction (Adams, 1991; Hart-Smith and Thrall, 1985). The presence of stress concentrations at the edges of a joint combined with a lightly loaded though useful region of the adhesive at the center has led to techniques, such as increased overlaps and tapered adherents, which reduce the magnitude of the near-edge stresses. In addition, several stress-based failure criteria have been proposed. One of the most notable is Hart-Smith's approach (Hart-Smith, 1973) which states that the bond strength is limited by the adhesive shear strain energy per 
unit bonded area. To date, the stress-based approach to bonded joint design has functioned well. It has been incorporated into computerized design programs used in the aerospace industry and has contributed to the success of the USAF's PABST program and subsequent adhesively bonded designs (Tomblin et al., 1998).

Azari et al. $(2011 \mathrm{a}, \mathrm{b})$ studied the effect of bondline thickness on the fatigue and fracture of aluminum adhesive joints bonded using a rubber-toughened epoxy adhesive using finite element analysis. The fracture data illustrates the relation between the adhesive thickness and the quasistatic crack initiation and steady-state critical strain energy release rates. Rabinovitch (2008) studied a linear elastic fracture mechanics (LEFM) approach and a cohesive interface (cohesive zone) modeling approach to the debonding analysis of concrete beams strengthened with externally bonded fiber-reinforced-polymer (FRP) strips. The LEFM model combined stress analysis using a high order theory and fracture analysis using the concepts of the energy release rate and the J-integral. Bocciarelli et al. (2009) investigated the debonding strength of axially loaded double shear lap specimens between steel plates and a carbon fibre reinforced plastic. Failure of the steel-adhesive interface has been identified as the dominant failure mode and fracture mechanics, and a stress based approach has been presented in order to estimate the relevant failure load.

Lenwari et al. (2012) addresses the debonding strength of adhesive-bonded double-strap steel joints. A fracture-based criterion has been formulated in terms of a stress singularity parameter. The test results showed that the interfacial failure near the steel/adhesive corner was the dominant failure mode. The failure was brittle and the debonding life was governed by the crack initiation stage. The finite element analysis was employed to calculate the stress intensity factors and investigate the effects of the adhesive layer thickness, lap length and joint stiffness ratio on the debonding strength.

In this work, fracture mechanics is used to predictcrack propagation in the joint between aluminum and composite plates. The setup considered in this work is shown in Fig. 1. Three types of loadings: $\lambda=0, \lambda=0.5$ and $\lambda=1$ (the parameter $\lambda$ is defined as the fraction of the lateral loading from the total loading; i.e. $\lambda=0$ means the loading is completely in plane and $\lambda=1$ means the loading is completely lateral) are considered, while two types of glass-epoxy composite sequences: $[0 / 90]_{2 \mathrm{~s}}$ and $[0 / 45 /-45 / 90]_{\mathrm{s}}$ are considered for the composite plate. Therefore, $2 \times 3=6$ cases are considered in this study, and their results are compared. Afterwards, the sequence $[0 / 90]_{2 \mathrm{~s}}$ is called sequence 1 , and $[0 / 45 /-45 / 90]_{\mathrm{s}}$ is called sequence 2 . Half of a typical crack face shape is shown in Fig. 2 for the symmetrical problem considered in this work.

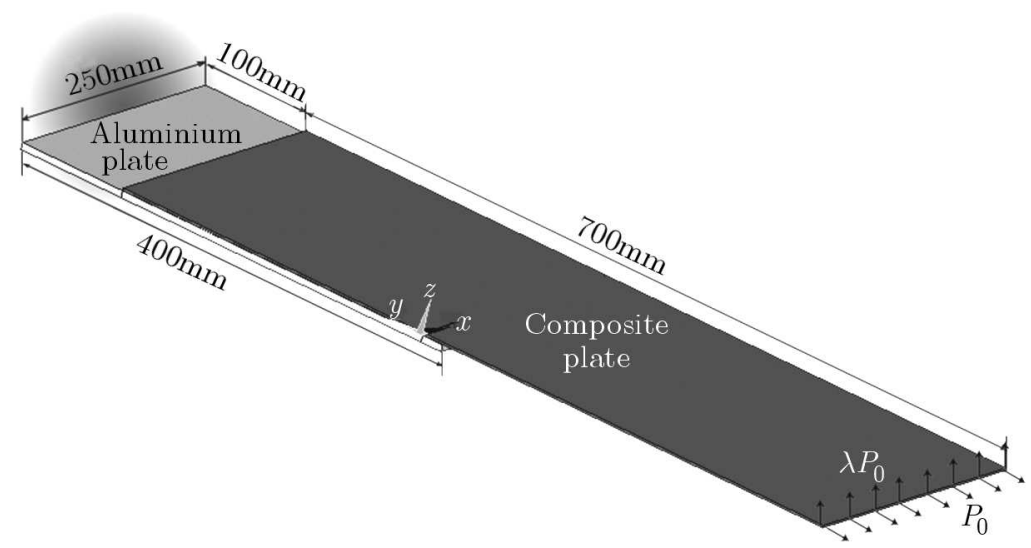

Fig. 1. The composite/aluminum joint studied 


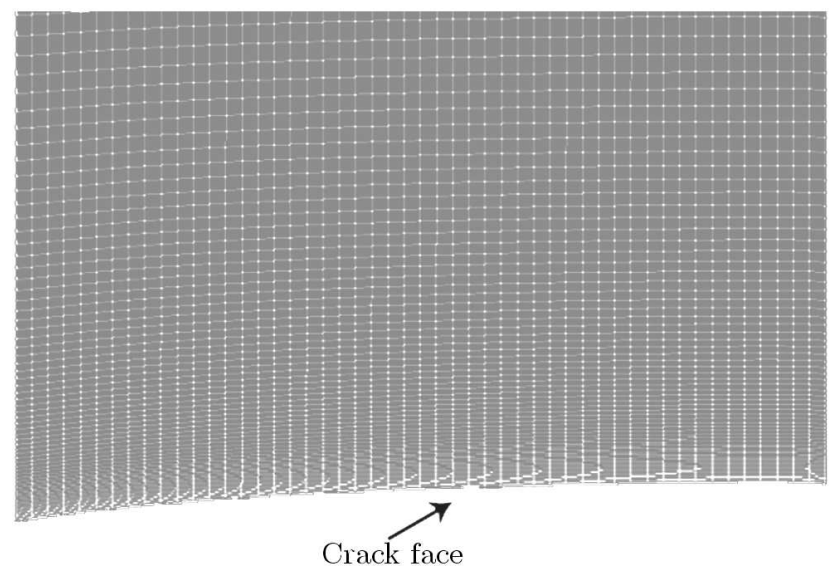

Fig. 2. Shape of a typical crack face

\section{The crack propagation criteria}

The main parameter in analyzing crack propagation is called the stress intensity factor which is respectively shown by $K_{I}, K_{I I}$ and $K_{I I I}$ for opening, shearing, and out of plane shearing fracture modes. The stress intensity factor is the representative of stress intensity around a crack or crack tip or face. In first fracture mode (the opening mode), the stress around a crack tip can be calculated using the following equations

$$
\begin{aligned}
\sigma_{11} & =\frac{K_{I}}{\sqrt{2 \pi r}} \cos \frac{\theta}{2}\left(1-\sin \frac{\theta}{2} \sin \frac{3 \theta}{2}\right) \quad \sigma_{22}=\frac{K_{I}}{\sqrt{2 \pi r}} \cos \frac{\theta}{2}\left(1+\sin \frac{\theta}{2} \sin \frac{3 \theta}{2}\right) \\
\sigma_{12} & =\frac{K_{I}}{\sqrt{2 \pi r}} \sin \frac{\theta}{2} \cos \frac{\theta}{2} \cos \frac{3 \theta}{2}
\end{aligned}
$$

By considering $\theta=0$

$$
\sigma_{22}=\frac{K_{I}}{\sqrt{2 \pi r}} \rightarrow K_{I}=\sigma_{22} \sqrt{2 \pi r}
$$

In the second fracture mode (the shearing mode), the relationship between the stresses and $K_{I I}$ is

$$
\begin{aligned}
\sigma_{11} & =\frac{-K_{I I}}{\sqrt{2 \pi r}} \sin \frac{\theta}{2}\left(2+\cos \frac{\theta}{2} \cos \frac{3 \theta}{2}\right) \\
\sigma_{12} & =\frac{-K_{I I}}{\sqrt{2 \pi r}} \cos \frac{\theta}{2}\left(1-\sin \frac{\theta}{2} \sin \frac{3 \theta}{2}\right)
\end{aligned} \quad \sigma_{22}=\frac{-K_{I I}}{\sqrt{2 \pi r}} \sin \frac{\theta}{2} \cos \frac{\theta}{2} \cos \frac{3 \theta}{2}
$$

By considering $\theta=0$

$$
\sigma_{12}=\frac{-K_{I I}}{\sqrt{2 \pi r}} \rightarrow K_{I I}=-\sigma_{12} \sqrt{2 \pi r}
$$

In this paper, crack propagation in the adhesively joined composite and aluminum plates is studied. For investigating crack propagation in static loading, two criteria are needed: initiation criteria and propagation criteria. The crack propagates through the middle of the adhesive layer, relatively distant from either adhesive-adherent interface, leaving an adhesive layer on both adherents (Tomblin et al., 1998).

In order to find the shape and size of the initial crack, a simple method is used. After applying the load, initial debonding is made at the locations in which the $Y Z$ shear stress is higher than 
the adhesive shear yield stress. The crack initiation load is the load which (after creating the initial debonding) satisfies the propagation criteria on the nodes located on the crack front to a small extent.

The crack propagation criteria used in this study is (Hosseini-Toudeshky et al., 2006)

$$
\frac{G_{I}}{G_{I c}}+\frac{G_{I I}}{G_{I I c}}+\frac{G_{I I I}}{G_{I I I c}}=1
$$

Using $G=K^{2} / E$ and by considering only the first and the second mode of fracture

$$
\left(\frac{K_{I}}{K_{I c}}\right)^{2}+\left(\frac{K_{I I}}{K_{I I c}}\right)^{2}=1
$$

In order to calculate $K_{I}$ and $K_{I I}$, the following substitutions are made to equations (2.2) and $(2.4)$

$$
\sigma_{22}=\sigma_{z z} \quad \sigma_{12}=\sigma_{y z}
$$

where the $X, Y$ and $Z$ directions are shown in Fig. 1.

In this study, the adherent chosen for bonding the aluminum and composite plates is FM73. The material properties of the FM73 adhesive are listed in Table 1 (Tomblin et al., 1998).

Table 1. Material properties of the FM73 adhesive

\begin{tabular}{|l|c|}
\hline \multicolumn{1}{|c|}{ Property } & Amount \\
\hline \hline Elasticity modulus & $1.83 \mathrm{GPa}$ \\
\hline Yield stress & $43 \mathrm{MPa}$ \\
\hline$K_{I c}$ & $2263600 \mathrm{~Pa} \sqrt{\mathrm{m}}$ \\
\hline$K_{I I c}$ & $2530810 \mathrm{~Pa} \sqrt{\mathrm{m}}$ \\
\hline
\end{tabular}

\section{Finite element modeling}

In this project, a macro program is developed using ANSYS Parametric Design Language (APDL) to model the debonding growth. At each step, the debonding face propagation, which is non-uniform, is calculated. Then the elements are completely cleared and a new model which consists of the updated crack face is created and then meshed. This mesh deletion and creation is done ateach propagation step in order to keep the accuracy of calculations well. The major steps of the developed macro programare as follows:

(1) Define material properties of the model.

(2) Define the crack initiation load.

(3) Generate geometry and mesh of the composite and aluminum plates and the adhesive.

(4) Define the loading and constraints.

(5) Perform the linear elastic solution.

(6) Predict the initial debonding area using the crack initiation criterion.

(7) Move all the nodes located on the crack front by $0.2 \mathrm{~mm}$ in the positive $Y$ direction.

(8) Perform the linear elastic solution.

(9) Calculate the stress intensity factors $\left(K_{I}\right.$ and $\left.K_{I I}\right)$ at each node located on the crack face.

(10) Move back the nodes which have not satisfied the propagation criterion to their previous location (move them back by $0.2 \mathrm{~mm}$ in the negative $Y$ direction). 
(11) If none of the nodes located on the crack front satisfy the propagation criterion, increase the applied load.

(12) If the crack has reached its end (it has moved $300 \mathrm{~mm}$ ), stop the solution.

(13) Return to step (8).

The finite element model of the problem is shown in Fig. 3, and is zoomed in at the adhesive interface in Fig. 4. For the composite plate 6000 8-noded SOLID46 elements, for the aluminum plate 22000 8-noded SOLID45 elements and for the adhesive 8000 SOLID45 elements have been used. For the composite plate, the aluminum plate and the adhesive, one, four and two elements through the thickness have been used. The elements at the two interfaces are glued. In other words, the composite and the adhesive share the same nodes at their interface. The same is true about the aluminum and the adhesive interface. This can be better seen in Fig. 4. Since the structure is symmetrical with respect to a plane perpendicular to the $X$ direction, only half of the model is created. The nodes located at the symmetry plane position are not allowed to move in the $X$ direction. For discretizing the entire model, mapped meshing has been used.

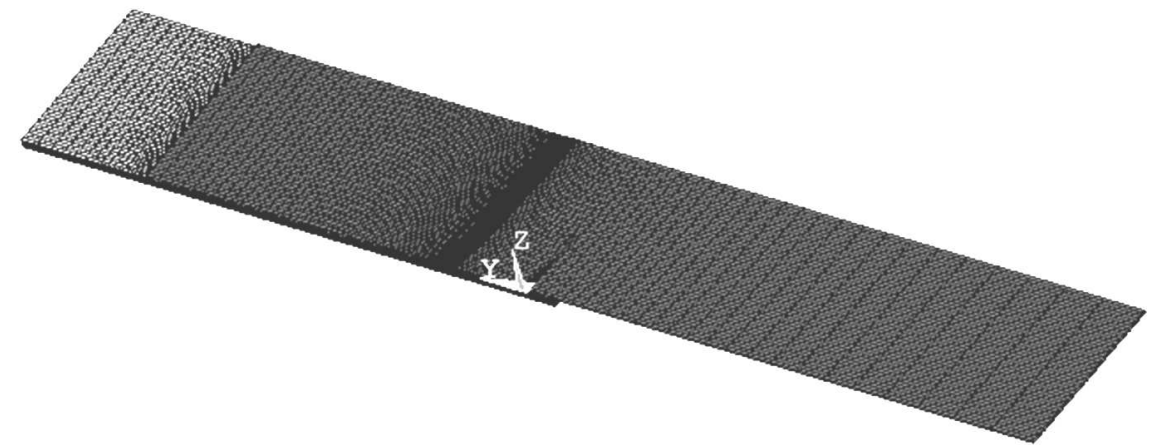

Fig. 3. Finite element model of the aluminum/composite joint

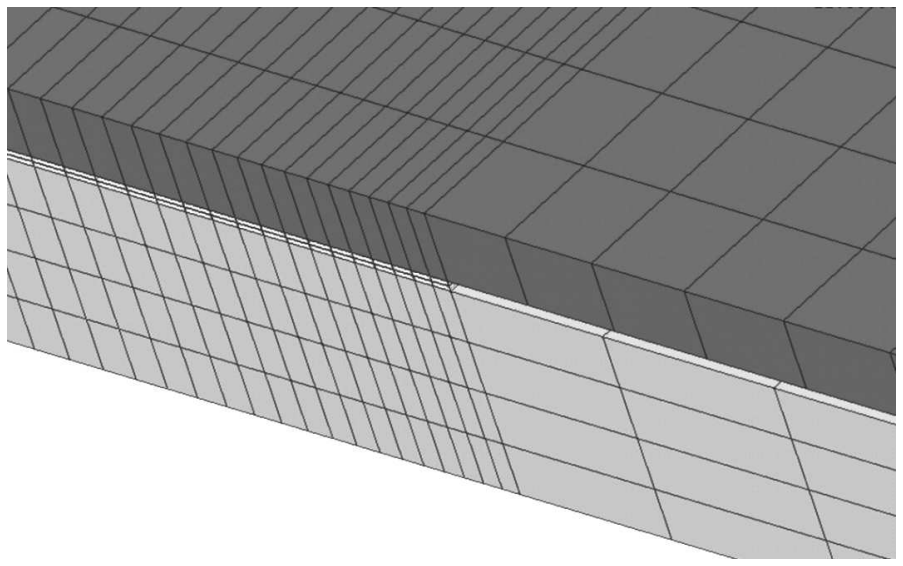

Fig. 4. Finite element model of the aluminum/composite joint (zoomed in)

Using a Core2Due 2.26 GHz CPU, each crack propagation step takes about two minutes. For each load step, about 400 propagation steps are needed. It must be noted that the crack initially moves quickly, but near the end of crack propagation at each load step, a long time is taken to move forward and backward most of the nodes on the crack face. Considering 4 to 6 load steps, solving each problem (in this study 6 cases are considered) takes about 40 hours. 


\section{Results and discussion}

\subsection{Crack initiation load}

The load versus crack propagation for $\lambda=0$ and for two composite sequences is shown in Fig. 5. As it can be seen, the crack initiation loads for the first and the second sequence are $232 \mathrm{kN} / \mathrm{m}$ and $224 \mathrm{kN} / \mathrm{m}$, respectively. It can also be seen that the complete debonding loads for the first and the second sequence are $656 \mathrm{kN} / \mathrm{m}$ and $496 \mathrm{kN} / \mathrm{m}$, respectively. Therefore, it can be concluded that the crack initiation load is close for the two sequences, but as the crack propagates, the load necessary for crack propagation is lower in sequence 2 than that in sequence 1.

The load versus crack propagation for $\lambda=0.5$ and $\lambda=1$ and for two composite sequences are shown in Fig. 5b. The initiation and the complete debonding load for the two composite sequences and for three values of $\lambda$ are listed in Tables 2 and 3. The following conclusions can be made:

- when $\lambda=0.5$ or 1 , by increasing the load slightly over the crack initiation load, the crack propagates immediately by about $150 \mathrm{~mm}$ (Fig. 5b). But on the other hand, it can be seen from Fig. 5a that when $\lambda=0$, by increasing the load slightly over the crack initiation load, the crack propagates immediately only by about $50 \mathrm{~mm}$ which is much lower than $150 \mathrm{~mm}$;

- for all values of $\lambda$, the initiation and the complete debonding load is lower in the cases with composite sequence 2 ;

- in both composite sequences, the initiation and the complete debonding load is higher for $\lambda=0.5$ than for $\lambda=1$.
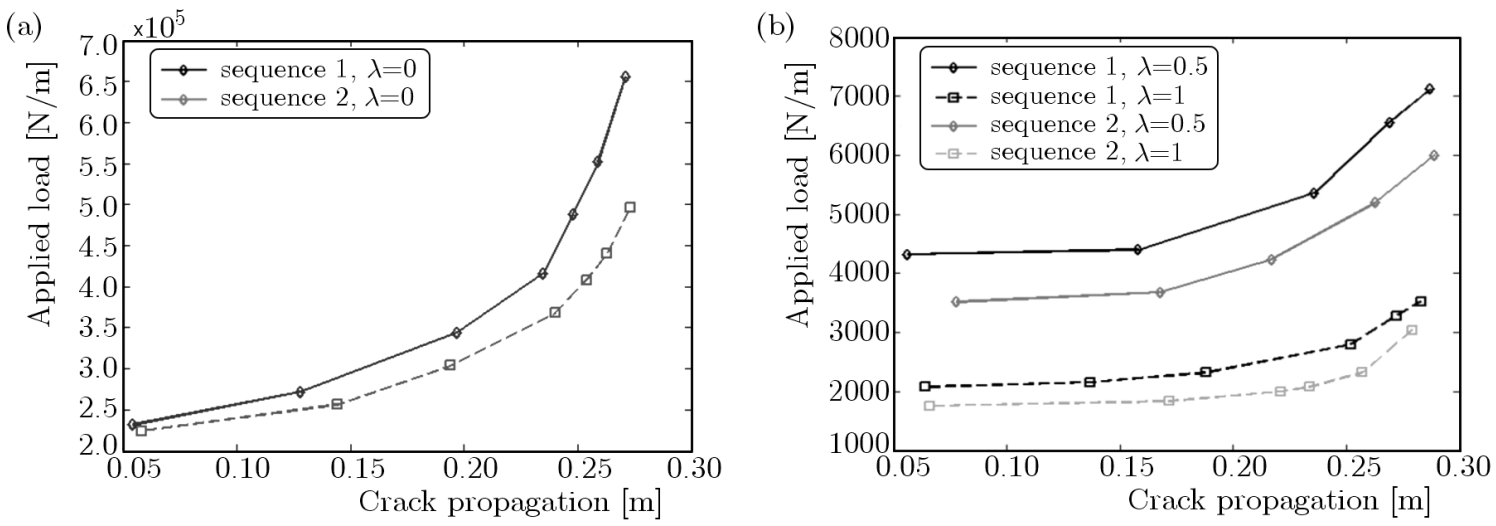

Fig. 5. Load versus crack propagation for: (a) two composite sequences $(\lambda=0)$ and (b) four composite sequences $(\lambda=0.5$ and $\lambda=1)$

Table 2. Crack initiation load for the six cases considered

\begin{tabular}{|c|c|c|c|}
\hline & $\lambda=1$ & $\lambda=0.5$ & $\lambda=0$ \\
\hline \hline Sequence 1 & $2.08 \mathrm{kN} / \mathrm{m}$ & $4.32 \mathrm{kN} / \mathrm{m}$ & $232 \mathrm{kN} / \mathrm{m}$ \\
\hline Sequence 2 & $1.76 \mathrm{kN} / \mathrm{m}$ & $3.52 \mathrm{kN} / \mathrm{m}$ & $224 \mathrm{kN} / \mathrm{m}$ \\
\hline
\end{tabular}

Table 3. Complete debonding load for the six cases considered

\begin{tabular}{|c|c|c|c|}
\hline & $\lambda=1$ & $\lambda=0.5$ & $\lambda=0$ \\
\hline \hline Sequence 1 & $3.52 \mathrm{kN} / \mathrm{m}$ & $7.12 \mathrm{kN} / \mathrm{m}$ & $656 \mathrm{kN} / \mathrm{m}$ \\
\hline Sequence 2 & $3.04 \mathrm{kN} / \mathrm{m}$ & $6 \mathrm{kN} / \mathrm{m}$ & $496 \mathrm{kN} / \mathrm{m}$ \\
\hline
\end{tabular}




\subsection{Crack face profile}

The crack face profile in different crack propagations can be seen in Fig. 6(a-d) for the two sequences and $\lambda=0$ and 1 . The difference between the debonding propagations of the ends and the middle of the debonding front is listed for the six cases in Table 4. The oscillations visible in the profiles are because of two reasons:

- Firstly, for better visibility of the crack face profiles for different crack propagations, the crack dimension in the $Y$ direction (parallel to the direction in which the crack moves) is scaled by about 10 times in Fig. 6(a-d). Therefore, the real oscillations in the crack profile are exaggerated in plots.

- Secondly, since each node is allowed to move forward and backward only by $0.2 \mathrm{~mm}$, the crack face profile cannot be completely smooth. By decreasing the value of the movement, a smoother crack face profile can be obtained.
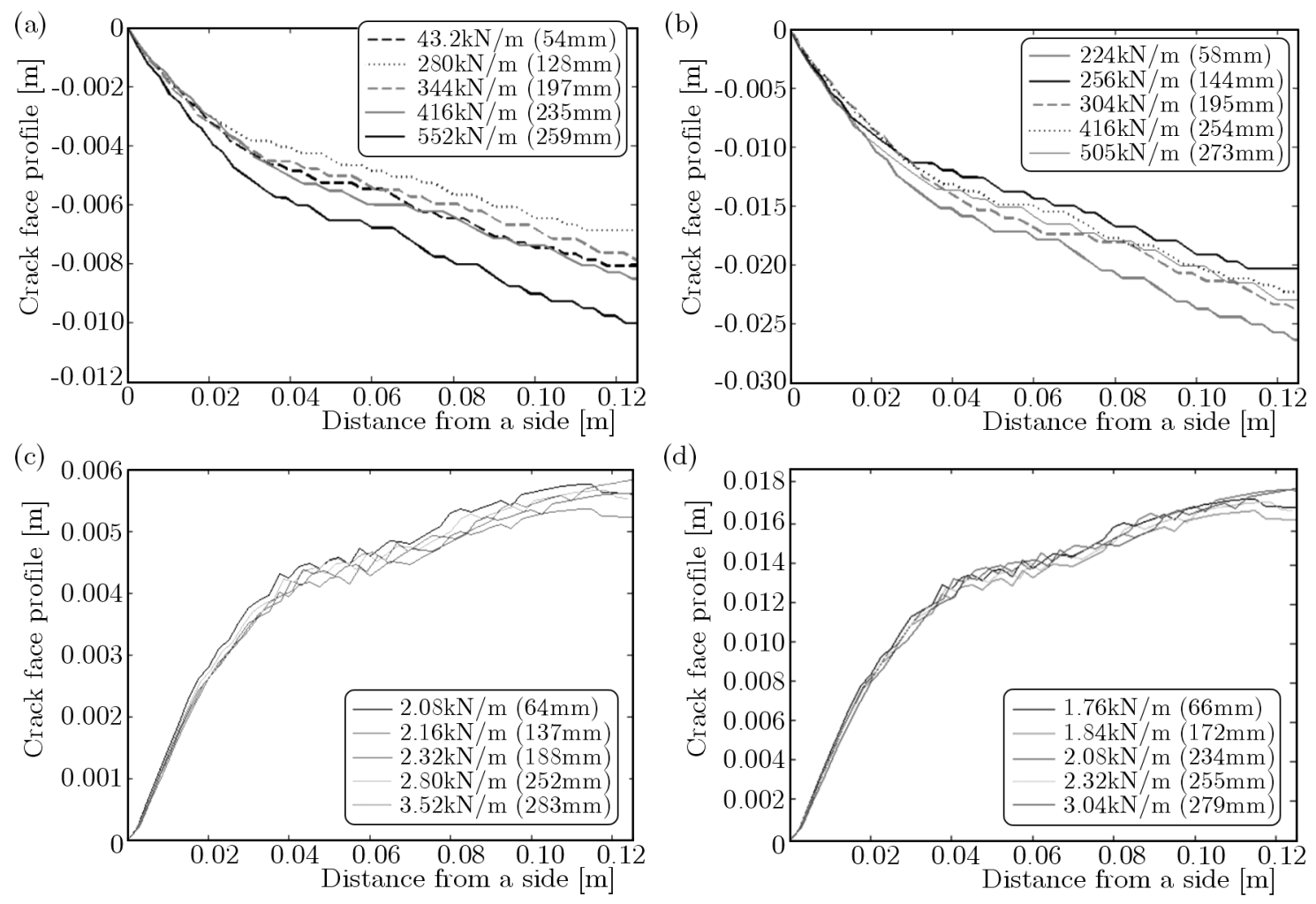

Fig. 6. Comparison of the crack face profile for different crack propagations: (a) sequence 1 and $\lambda=0$, (b) sequence 2 and $\lambda=0,(\mathrm{c})$ sequence 2 and $\lambda=0$, (d) sequence 2 and $\lambda=1$

Table 4. Difference of crack propagation between the ends and middle parts of the crack face

\begin{tabular}{|c|c|c|c|}
\hline & $\lambda=0$ & $\lambda=0.5$ & $\lambda=1$ \\
\hline \hline Sequence 1 & $10 \mathrm{~mm}$ & $7.2 \mathrm{~mm}$ & $5.9 \mathrm{~mm}$ \\
\hline Sequence 2 & $26 \mathrm{~mm}$ & $15 \mathrm{~mm}$ & $17 \mathrm{~mm}$ \\
\hline
\end{tabular}

It can be seen in Fig. 6(a-d) and Table 4 that:

- For both sequence types and with $\lambda=0$, the ends of the crack face propagates forward more than its middle part, while with $\lambda=0.5$ or $\lambda=1$, the middle part of the crack face moves forward more than its ends. 
- For all values of $\lambda$, the difference between the debonding propagations of the ends and the middle of the crack face for composite sequence of 2 is higher than that for sequence 1. This can be more recognized when $\lambda=0$.

- For both sequence types, the difference between the debonding propagations of the ends and the middle of the crack face with $\lambda=0$ is higher than that in the corresponding case with $\lambda=0.5$ or $\lambda=1$.

- Regardless of the sequence type, when $\lambda=0$ the debonding face profile can be divided in three regions: (a) at the beginning of debonding propagation, the difference between the debonding propagations of the ends and the middle of the crack face is small, (b) when the maximum propagation of the crack face is higher than $50 \mathrm{~mm}$, the difference between the debonding propagations of the ends and the middle of the crack face gets larger and remains almost constant until near the end of propagation, and (c), when the crack face has reached near the end of the adhesive film, the difference between the debonding propagations of the ends and the middle of the crack face gets small again.

- Regardless of the sequence type, when $\lambda=0.5$ or $\lambda=1$, the difference between the debonding propagations of the ends and the middle of the crack face gets larger consistently. In other words, the difference between the debonding propagations of the ends and the middle of the crack face is small at the beginning, then for a large range of the debonding propagation remains almost constant, and finally at the end of propagation gets large.

- For any value of $\lambda$, the difference between the debonding propagations of the ends and the middle of the crack face is very close for $\lambda=0.5$ and $\lambda=1$.

\subsection{Load-displacement diagrams}

For plotting the load-displacement diagram, the displacement at the end of the composite plate is measured. For $\lambda=0$, the horizontal displacement and for $\lambda=0.5$ and 1 , the vertical displacement is measured. This is also true for $\lambda=0.5$, because the horizontal displacement of the composite end is negligible as compared to its vertical displacement. The load-displacement diagrams for the six cases are plotted in Fig. 7(a-f). The following conclusions can be made:

- The change in the load-displacement slope from the initial debonding until the complete debonding in the cases with $\lambda=0.5$ and 1 is more than that in the cases with $\lambda=0$.

- Regardless of the composite sequence, if $\lambda=0$, the complete debonding happens when the displacement at the end of the composite plate reaches $1 \mathrm{~cm}$.

- Regardless of the composite sequence, if $\lambda=0.5$ and 1 , the complete debonding happens when the displacement at the end of the composite plate reaches $16 \mathrm{~cm}$.

The load-displacement diagrams at the complete debonding is compared for the two sequences and $\lambda=0.5$ and 1 in Fig. 8. It is interesting to see that the sequence type does not affect the load-displacement slope very much. On the other hand, the value of $\lambda$ has a significant effect on the slope of the load-displacement diagram.

\section{Conclusions}

In this work, fracture mechanics methodology is used to predict crack propagation in the adhesive joining of aluminum and composite plates. Three types of loadings: $\lambda=0, \lambda=0.5$ and $\lambda=1$ are considered while two types of glass-epoxy composite sequences: $[0 / 90]_{2 \mathrm{~s}}$ and $[0 / 45 /-45 / 90]_{\mathrm{s}}$ are considered for the composite plate. Therefore, $2 \times 3=6$ cases are considered in this study, and their results are compared. It is observed that the crack initiation load is close for the two sequences, but as the crack propagates, the load necessary for crack propagation is lower in 

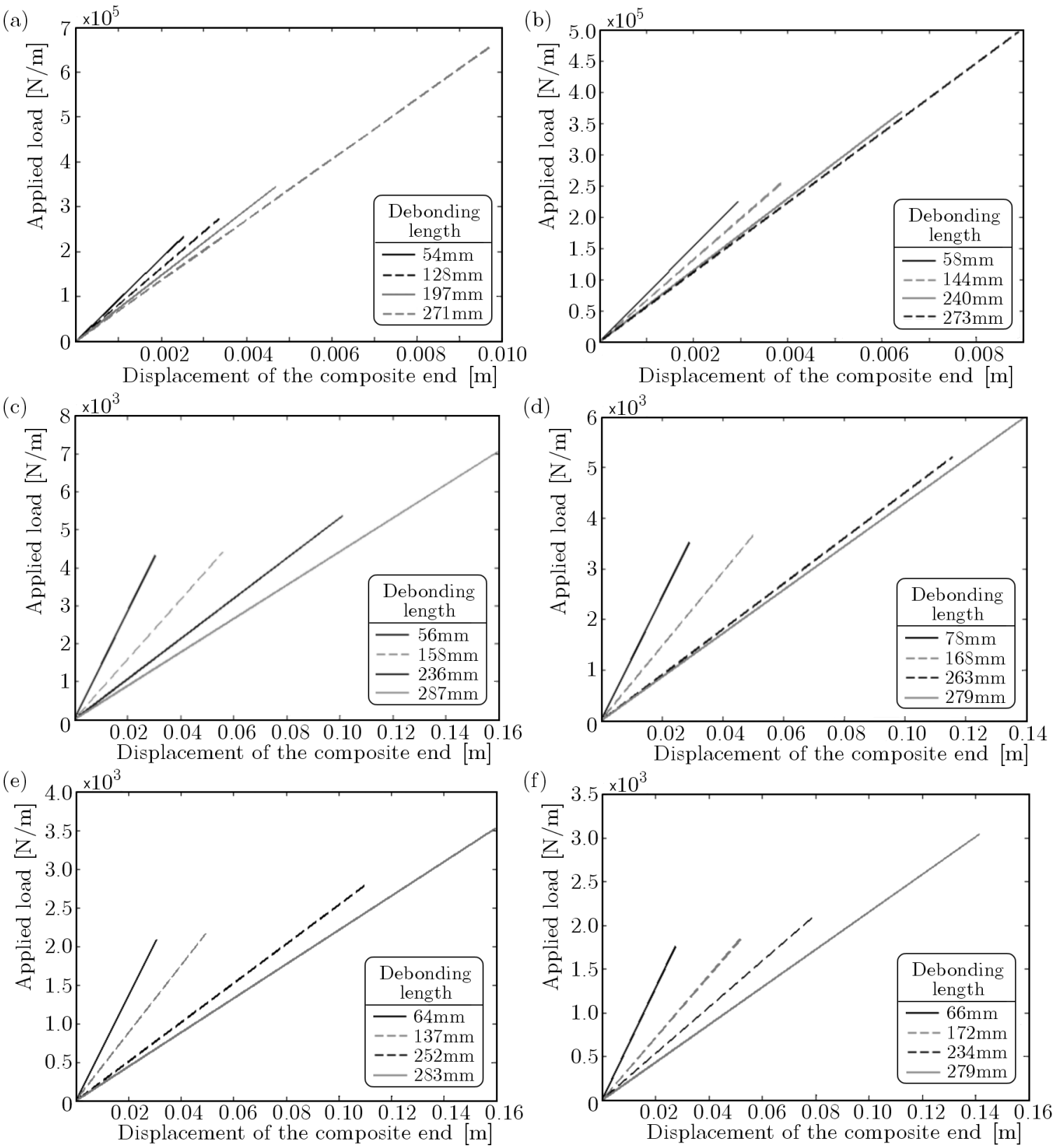

Fig. 7. Load-displacement diagrams for: (a) sequence 1 and $\lambda=0$, (b) sequence 2 and $\lambda=0$, (c) sequence 1 and $\lambda=0.5$, (d) sequence 2 and $\lambda=0.5$, (e) sequence 1 and $\lambda=1$, (f) sequence 2 and $\lambda=1$

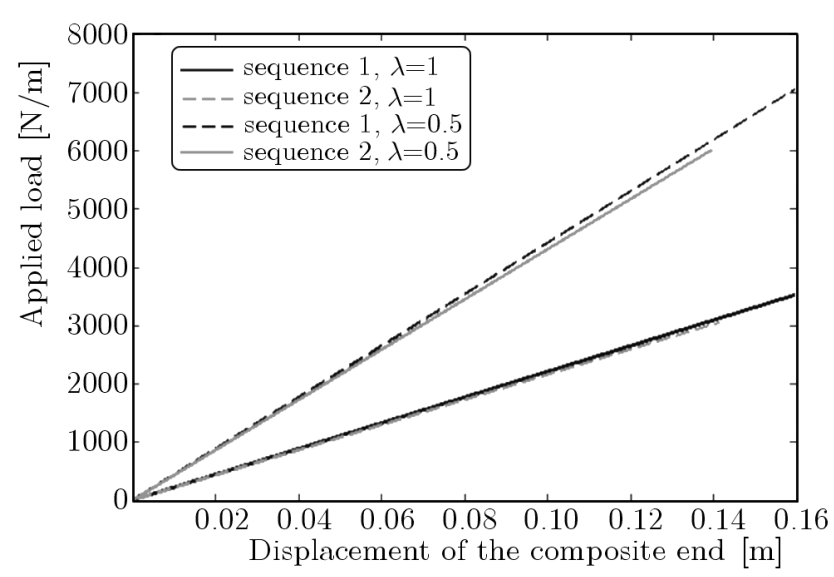

Fig. 8. Comparison of load-displacement diagrams near the complete debonding for the two sequences and $\lambda=0.5$ and 1 
sequence $[0 / 45 /-45 / 90]_{\mathrm{s}}$ than that in sequence $[0 / 90]_{2 \mathrm{~s}}$. As for the debonding front profile, it has been seen that for both sequence types, in the cases with $\lambda=0$, the side parts of the debonding front propagates more forward than its middle part, while in the cases with $\lambda=0.5$ or $\lambda=1$, the middle part of the debonding front moves forward more than its side parts. It has been also seen that regardless of the $\lambda$ value, the difference between the debonding propagations of the side and the middle parts of the debonding front is very close for $\lambda=0.5$ and $\lambda=1$. In the loaddisplacement diagram, it is seen that the sequence type does not affect the load-displacement slope very much. On the other hand, the value of $\lambda$ has a significant effect on the slope of the load-displacement diagram.

\section{References}

1. Adams R.D., 1991, Testing of adhesives-useful or not? [In:] Adhesion 15: Proceedings of the 28th Annual Conference on Adhesion and Adhesives, K.W. Allen (Edit.), Elsevier Applied Science Publishers, London, UK

2. Azaria S., Papinib M., Spelt J.K., 2011a, Effect of adhesive thickness on fatigue and fracture of toughened epoxy joints, Part I: Experiments, Engineering Fracture Mechanics, 78, 1, 153-162

3. Azaria S., Papinib M., Spelt J.K., 2011b, Effect of adhesive thickness on fatigue and fracture of toughened epoxy joints, Part II: Analysis and finite element modeling, Engineering Fracture Mechanics, 78, 1, 138-152

4. Bocciarelli M., Colombi P., Fava G., Poggi C., 2009, Prediction of debonding strength of tensile steel/CFRP joints using fracture mechanics and stress based criteria, Engineering Fracture Mechanics, 76, 2, 299-313

5. Goland M., Reissner E., 1944, The stresses in cemented joints, Journal of Applied Mechanics, 11

6. Hart-Smith L.J., 1973, Adhesive-Bonded Double-Lap Joints, Douglas Aircraft Co., Long Beach, CA, for NASA Langley Research Center, NASA CR-112235

7. Hart-Smith L.J., 1983, Adhesive bonding of aircraft primary structures, [In:] High Performance Adhesive Bonding, G. DeFrayne (Edit.), Society of Manufacturing Engineers, Dearborn, MI

8. Hart-Smith L.J., Thrall E.W., 1985, Structural analysis of adhesive-bonded joints, [In:] Adhesive Bonding of Aluminum Alloys, E.W. Thrall and R.W. Shannon (Edit.), Marcel Dekker, Inc., New York, NY

9. Hosseini-Toudeshiy H., Mohammadi B., Hamidi B., Ovesy H.R., 2006), Analysis of composite skin/stiffener debounding and failure under uniaxial loading, Composite Structures, 75, $428-436$

10. Lenwari A., Thepchatri T., Santisukpotha P., 2012), A fracture-based criterion for debonding strength of adhesive-bonded double-strap steel joints, Engineering Journal, 16, 1, 17-26

11. Rabinovitch O., 2008, Debonding analysis of fiber-reinforced-polymer strengthened beams: Cohesive zone modeling versus a linear elastic fracture mechanics approach, Engineering Fracture Mechanics, 75, 10, 2842-2859

12. Tomblin J., Seneviratne W., Escobar P., Yoon-Khian Y., 1998, Applications of fracture mechanics to the durability of bonded composite joints, DOT/FAA/AR-97/56 